\title{
Effectiveness of Bacillus Calmette-Guerin for Tuberculosis Prevention Among Chinese People: Systematic Review and Meta-analysis
}

\author{
Xiaoyan Yang ${ }^{1, *}$ and Hailong Zhou ${ }^{2}$ \\ ${ }^{I}$ West China Hospital/West China School of Medicine, Sichuan University, Chengdu 610041, China \\ ${ }^{2}$ West China School of Public Health, Sichuan University, Chengdu 610041, China
}

\begin{abstract}
Background: Our previous study showed that the protective effect of Bacillus Calmette-Guerin (BCG) declined with time, which is supported by a following study saying "BCG vaccination protection against tuberculosis varies between populations, to an extent that cannot be attributed to chance alone". Objective: To investigate BCG protective effect among Chinese people, so as to update the development and use of immunological agents. Methods: Systematic review was carried out: electronic databases searches, screening of identified studies based on inclusion and exclusion criteria, data extraction and meta-analysis were undertaken. Results: Initial search identified 3067 articles from four Chinese databases, after selection, 25 met the eligibility criteria among which 6 were cohort studies and 19 were casecontrol studies, with the total participant of 1311758 and 5169 respectively. None of the experimental studies such as randomized controlled trials (RCTs) were identified. The P value of Egger's test was 0.016 for cohort studies and 0.067 for case-control studies, which, together with funnel plot, indicated that the available evidences were at risk of publication bias. The pooled estimate of RR for cohort studies was 0.24 , with $95 \%$ confidence interval $(95 \% \mathrm{CI})(0.11,0.52)$, and of OR for case-control studies it was 0.37 with $95 \% \mathrm{CI}(0.31,0.45)$. Conclusions: The available evidence shows positive and definite effect of BCG in preventing TB among Chinese people but it should be supported by more studies to avoid publication bias risk. High quality studies are encouraged worldwide to update the development and use of immunological agents to cope with tuberculosis epidemiology.
\end{abstract}

Keywords: Bacillus Calmette-Guerin (BCG), China, Meta-analysis, Observational study, Systematic review, Tuberculosis (TB).

\section{INTRODUCTION}

The trends in estimated tuberculosis (TB) incidence rates among 22 high-burden countries from 1990 to 2012 showed different patterns, such as declining (e.g. China), stable (e.g. Pakistan) and ascending (e.g. South Africa) [1], which, to some extent, reflect the comprehensive results of various factors including TB prevention and treatment endeavor. In China, the Bacillus Calmette-Guerin (BCG) was approved as the immunological preparation of the National Immunization Program for TB prevention since foundation of P.R. China, and each newborn was to be inoculated with the first dose. How about the evidence of its protection efficacy? We carried out a prior study, including randomized/quasirandomized controlled trails, showing that the 5 year and 10 year incidences of BCG were lower than that of the control in different settings worldwide, while the 15 year and 20 year incidence varied. Other researchers reported that BCG vaccination protection against $\mathrm{TB}$ varies between populations, to an extent that cannot be attributed to chance

*Address correspondence to this author at the West China Hospital/West China School of Medicine, Sichuan University, Chengdu 610041, China; Tel: 13551805288; E-mail: yangxy2002@126.com alone [2]. How about the evidence after several decades' application of BCG in China? We therefore now report a new systematic review and meta-analysis of the evidence available to evaluate the effectiveness of BCG for TB prevention among Chinese people, to inform immunological agent development and use.

\section{METHODS}

\subsection{Study Eligibility Criteria}

The inclusion criteria: studies that investigated effectiveness of $\mathrm{BCG}$ for $\mathrm{TB}$ prevention, targeting at individual Chinese.

The exclusion criteria: studies without control group or the comparison was not blank.

\subsection{Search Strategy}

Chinese databases of CBM, CNKI, VIP and WANFANG were searched from creations till February 2014 using keywords of BCG and TB, without limitation of study design, and the references of eligible studies were also searched. 


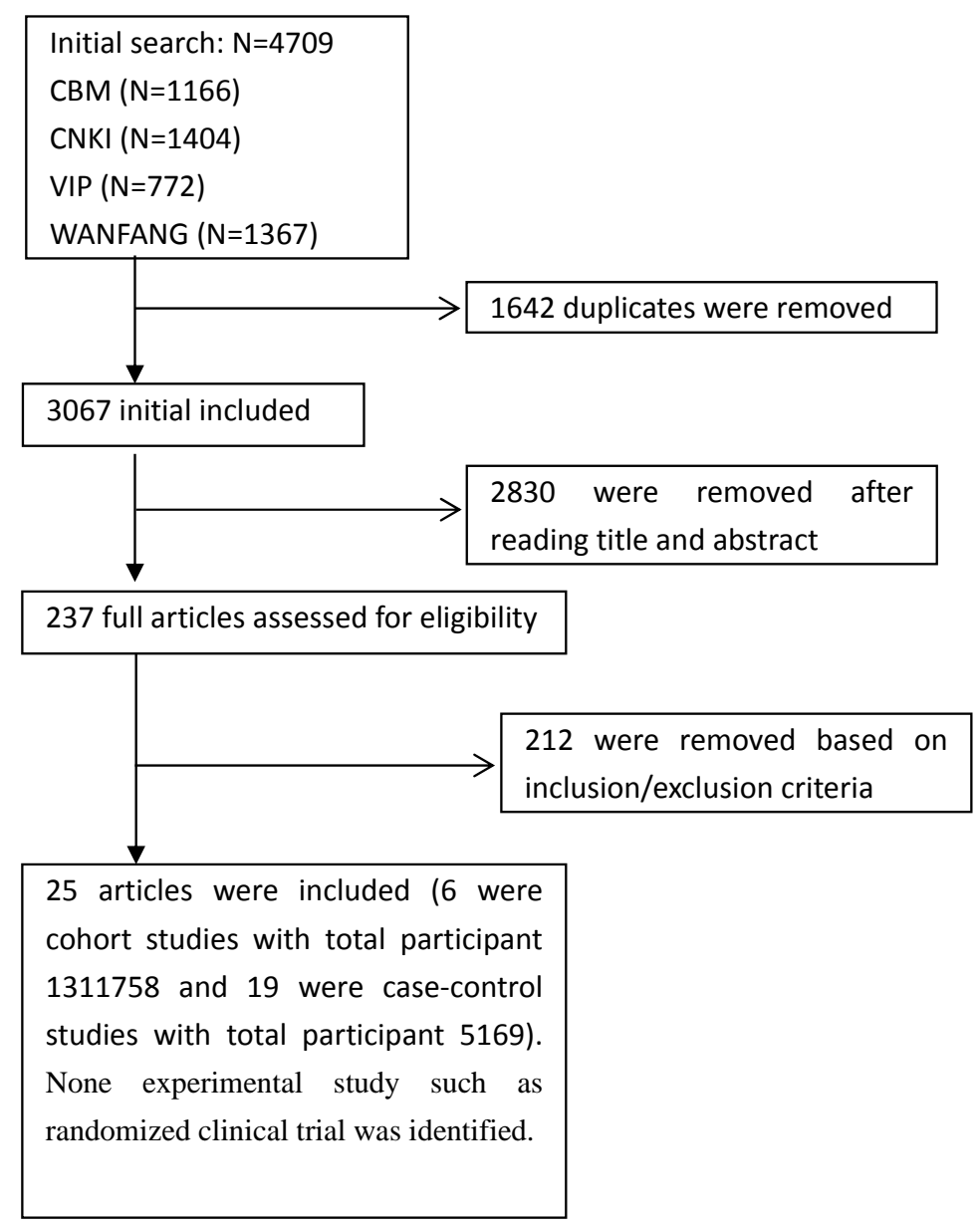

Fig. (1). Flow diagram of study searching and selection process.

\subsection{Quality Assessment in Individual Studies}

Two reviewers independently performed data extraction and quality assessment, disagreements were resolved by discussion. The Newcastle-Ottawa quality assessment scale (NOS) $[3,4]$ was used to evaluate the quality of included observational studies.

\subsection{Risk of Publication Bias Evaluation}

Software of Stata 12.0 was used to test publication bias. RevMan 5.2 was applied to draw the funnel plot.

\subsection{Statistical Analysis}

Statistical analysis was carried out using RevMan 5.2. All studies were grouped by study design, as prior protocol, to pool the whole effect. Heterogeneity was analyzed and the estimate was pooled for each level of the important heterogeneity factors. The fixed effect model was applied in groups without heterogeneity, and in the others (after analysis, heterogeneity exited yet) the random effect model was applied. Relative risk (RR) or odds ratio (OR) and their 95\% confidence interval $(95 \% \mathrm{CI})$ were used for binary variable. $\mathrm{P}$ values of less than 0.05 were considered as statistically significant for both heterogeneity test and the pooled estimates.

\section{RESULTS}

\subsection{Description of Study Identification}

The initial search identified 3067 articles, after title and abstract screening, 237 full-length papers were read carefully and 25 observational studies were included, among which 6 were cohort studies and 19 were case-control studies, none of the experimental studies such as RCTs were identified (Fig. 1).

\subsection{Characteristics of Included Studies and Quality Assessment}

Table 1 and Table $\mathbf{2}$ show the characteristics of cohort studies [5-10] and case-control studies [11-29] respectively.

The total sample size of six cohort studies is 1311758 . The start time varied from year 1968 to 2002, with a span from 1 to 30 years. The ratio of prospective versus retrospective design is $1: 1$.The targeted population is children or teen-agers and three out of six studies targeted at meningeal TB. The studies got a NOS score from 5 to 9 with an average of 6.3. The items on which studies did not perform generally well include "Selection of the unexposed cohort", "Control for important factor or additional factor" and "Follow-up long enough for outcomes to occur". 
Table 1. Characteristics of the included cohort studies.

\begin{tabular}{|c|c|c|c|c|c|c|c|c|}
\hline Study ID & Time & Setting & Design Type & $\begin{array}{c}\text { Sample } \\
\text { Size }\end{array}$ & Age Range & $\begin{array}{c}\text { Average } \\
\text { Age }\end{array}$ & Disease Type & NOS Score \\
\hline $\begin{array}{c}\text { Guo Chongzheng } \\
1990\end{array}$ & $1985-1987$ & Gaoping county & Retrospective & 93835 & $0-14$ & NA & Meningeal TB & 9 \\
\hline Guo Jinwu 2006 & $1995-1996$ & Wuhan city & Prospective & 5652 & $\begin{array}{c}14-25 \\
\text { (college } \\
\text { freshman) }\end{array}$ & 18.5 & $\mathrm{~TB}$ & 6 \\
\hline Hou Dongqing 2001 & $1968-1997$ & Zhuzhou city & Prospective & 140852 & $0-14$ & NA & TB & 6 \\
\hline $\begin{array}{c}\text { Huang Lianzhang } \\
1988\end{array}$ & $1980-1984$ & Yancheng city & Retrospective & 1064175 & 1 and 7 & NA & Meningeal TB & 6 \\
\hline Li Zhigang 1998 & 1994-1996 & Zhangjiakou city & Prospective & 6981 & $\begin{array}{c}17-20 \\
\text { (college } \\
\text { freshman) }\end{array}$ & 18.5 & Pulmonary TB & 6 \\
\hline Wu Xirong 2012 & 2002-2010 & Peking city & Retrospective & 263 & $0-17$ & 5.5 & Meningeal TB & 5 \\
\hline Total/average & & & & 1311758 & & & & 6.3 \\
\hline
\end{tabular}

Table 2. Characteristics of the included case-control studies.

\begin{tabular}{|c|c|c|c|c|c|c|c|c|}
\hline Study ID & Time & Setting/Population & n1:n2 & $\begin{array}{c}\text { Sample } \\
\text { Size }\end{array}$ & $\begin{array}{c}\text { Exposure } \\
\text { Measurement }\end{array}$ & $\begin{array}{l}\text { Age (Range or } \\
\text { Mean) }\end{array}$ & Disease Type & $\begin{array}{l}\text { NOS } \\
\text { Score }\end{array}$ \\
\hline Cui Xiwen 2007 & 2006 & Kunshan city & 1.05 & 190 & $\begin{array}{c}\text { History of BCG } \\
\text { inoculation }\end{array}$ & $20-60$ & $\begin{array}{c}\text { Pulmonary } \\
\text { TB }\end{array}$ & 7 \\
\hline Feng Fumin 2006 & 2004-2005 & Tangshan city & 0.63 & 224 & BCG scar & 44.25 & $\begin{array}{c}\text { Pulmonary } \\
\text { TB }\end{array}$ & 6 \\
\hline Feng Fumin 2007 & NA & Tangshan city & 0.62 & 227 & BCG scar & 44.38 & $\begin{array}{c}\text { Pulmonary } \\
\text { TB }\end{array}$ & 7 \\
\hline $\begin{array}{c}\text { Jiang Xuefeng } \\
2008\end{array}$ & $2005-2007$ & Yinchuan city & 0.67 & 298 & $\begin{array}{c}\text { History of BCG } \\
\text { inoculation }\end{array}$ & NA(adult) & TB & 7 \\
\hline Ji Chunmei 2006 & 2004 & Tangshan city & 1 & 248 & BCG scar & 47 & $\begin{array}{c}\text { Pulmonary } \\
\text { TB }\end{array}$ & 8 \\
\hline Li Shengtuan 1999 & $1992-1996$ & Troops & 0.5 & 239 & BCG scar & 21.6 & $\begin{array}{c}\text { Pulmonary } \\
\text { TB }\end{array}$ & 8 \\
\hline Liu Wei 2003 & 2001-2002 & Peking city & 0.6 & 244 & $\begin{array}{c}\text { History of BCG } \\
\text { inoculation }\end{array}$ & 27 & $\begin{array}{c}\text { Pulmonary } \\
\text { TB }\end{array}$ & 5 \\
\hline Liu Wei 2006 & 2001-2004 & Troops & 0.59 & 374 & $\begin{array}{c}\text { History of BCG } \\
\text { inoculation }\end{array}$ & NA(adult) & $\begin{array}{c}\text { Pulmonary } \\
\text { TB }\end{array}$ & 6 \\
\hline Li Zijian 2001 & 1998-1999 & Jinan city & 1 & 324 & BCG scar & 19 & TB & 8 \\
\hline Ma Shixue 2005 & 2004 & Tengzhou city & 1 & 224 & BCG scar & 53.53 & $\begin{array}{c}\text { Pulmonary } \\
\text { TB }\end{array}$ & 7 \\
\hline $\begin{array}{l}\text { Shi Qingming } \\
2002\end{array}$ & $1999-2000$ & Hefei city & 0.9 & 166 & BCG scar & $\begin{array}{l}\text { NA(undergraduat } \\
\text { e students) }\end{array}$ & $\begin{array}{c}\text { Pulmonary } \\
\text { TB }\end{array}$ & 6 \\
\hline Wang Zhibin 2002 & $1998-2000$ & $\begin{array}{c}\text { Southern part of } \\
\text { China }\end{array}$ & 0.5 & 414 & $\begin{array}{c}\text { History of BCG } \\
\text { inoculation }\end{array}$ & $18-52$ & TB & 7 \\
\hline
\end{tabular}


Table 2. contd...

\begin{tabular}{|c|c|c|c|c|c|c|c|c|}
\hline Study ID & Time & Setting/Population & n1:n2 & $\begin{array}{c}\text { Sample } \\
\text { Size }\end{array}$ & $\begin{array}{c}\text { Exposure } \\
\text { Measurement }\end{array}$ & $\begin{array}{c}\text { Age (Range or } \\
\text { Mean) }\end{array}$ & Disease Type \\
Score
\end{tabular}

NA: not available

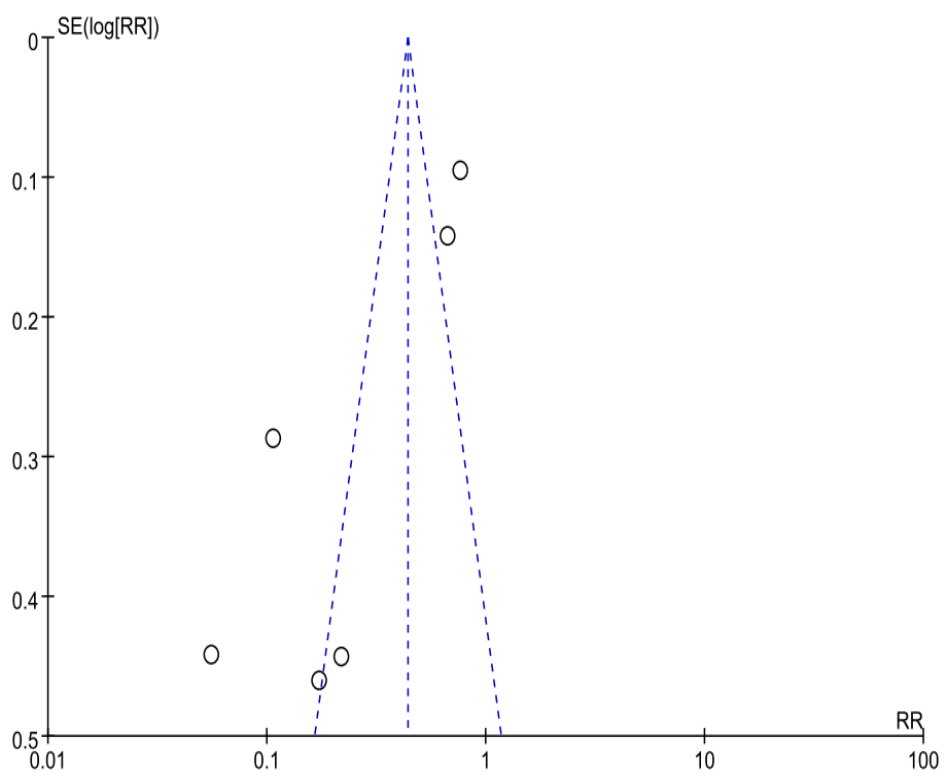

Fig. (2). Funnel plot for cohort studies.

The total sample size of case-control studies 5169. Most studies began in 1990s or later except for two (in 1980s). The targeted population is adult except for two targeted 0-14 years' children. Twelve out of nineteen studies targeted pulmonary TB. The studies got a NOS score from 5 to 8 with an average of 7.0. The items on which studies did not perform generally well include "Representativeness of cases", "Exposure assessment" and "Non-response rate".

\section{PUBLICATION BIAS}

Fig. (2) and Fig. (3) show respectively the funnel plot of cohort studies and of case-control studies, with $\mathrm{P}$ value of
Egger's test 0.016 and 0.067 respectively, implying that the symmetry is not good for both kind of study designs, especially for cohort study, and that the included studies are at risk of publication bias.

\subsection{Effectiveness of BCG for TB Prevention}

\subsubsection{Cohort Study}

Fig. (4) is the forest plot of BCG's prevention effect in cohort study. The overall effect (RR) for all is 0.24 with $95 \%$ CI $(0.11,0.52)$. The $\mathrm{P}$ value of heterogeneity test is far less than 0.05 with statistic I square of $95 \%$, statistically 


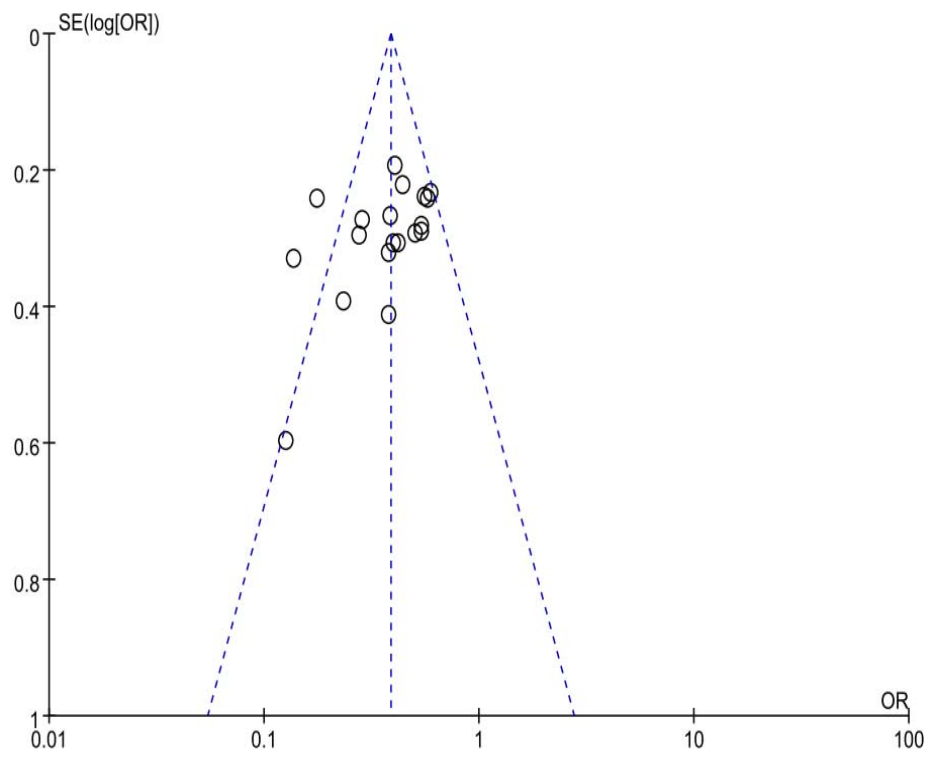

Fig. (3). Funnel plot for case-control studies.

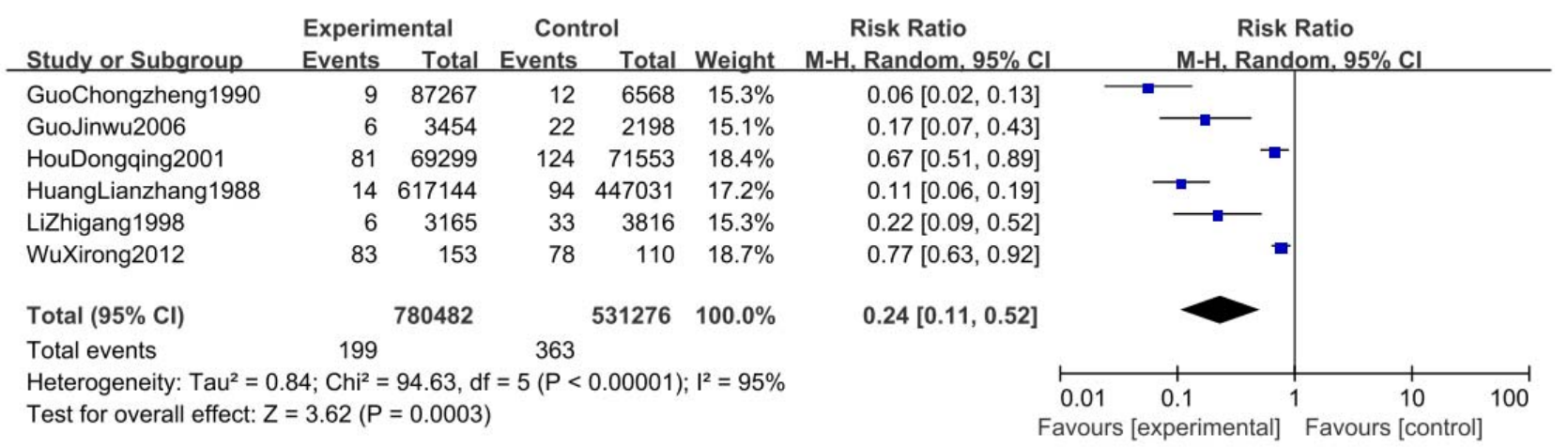

Fig. (4). The pooled estimate of BCG's protection effect in cohort study.

implying heterogeneity among studies. We then explored the factors which might contribute to the heterogeneity and carried out analysis in each level of potential factors, as shown in Fig. (5), displaying great improvement of the heterogeneity. The pooled value is statistically significant for each level of the factor, with pooled point estimate of RR 0.20 for those aged elder than 14. And for children not elder than 14 years old, it is 0.10 for studies not later than 1990 and 0.71 for studies after 1990 .

\subsubsection{Case-control Study}

Fig. (6) is the forest plot of BCG's prevention effect in case-control study. The overall effect OR is 0.37 with 95\%CI (0.31, 0.45).Similarly, the heterogeneity among studies is statistically significant, further analysis in Fig. (7) shows that the pooled point estimate of OR is $0.24,95 \% \mathrm{CI}$ $(0.14,0.40)$ for those aged not elder than 14 (the targeted disease type is TB meningitis for all ). And for those aged elder than 14 , it is $0.42(0.37,0.48)$ for those targeted at TB, and $0.14(0.07,0.26)$ for one study targeted at infiltrative pulmonary TB. The $\mathrm{P}$ value is less than 0.05 in all groups.

\section{DISCUSSION}

According to The Grading of Recommendations Assessment, Development, and Evaluation (GRADE) criteria [30, 31], the original studies included in this research are not of high quality at beginning (no RCTs are identified), however, it is reasonable to rate up the quality of the evidence, for the magnitude of pooled estimate of the effect is large enough: RR 0.24 for cohort studies and OR 0.37 for case-control studies. In addition, all the studies show consistent directions of BCG's positive effects, both between cohort and case-control study design and among articles in each study design group. Although it is not the reason to weigh, but it is a sound basis not to decline the quality [32], as it suggests good agreement with the studies, given that it is not affected by publication bias. In publication bias topic, our analysis shows that the included studies are at risk that, how it will result in the pooled estimate? It is worth further investigation and more researches are encouraged.

Heterogeneity analysis indicated that the time might be a source of heterogeneity, and based on professional knowledge and supported by literatures, we set the threshold 


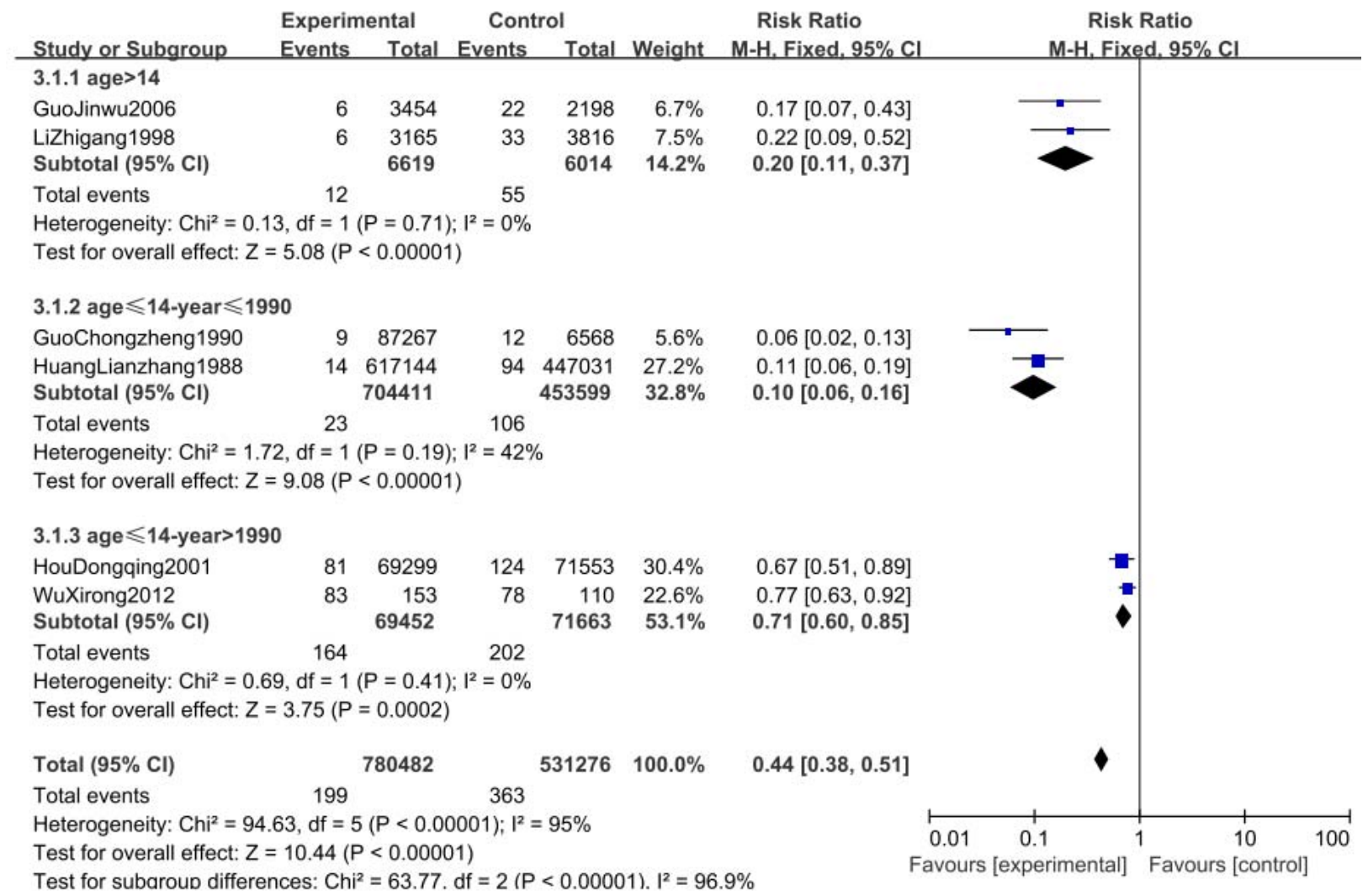

Fig. (5). The pooled estimate of BCG's protection effect in cohort study in group.

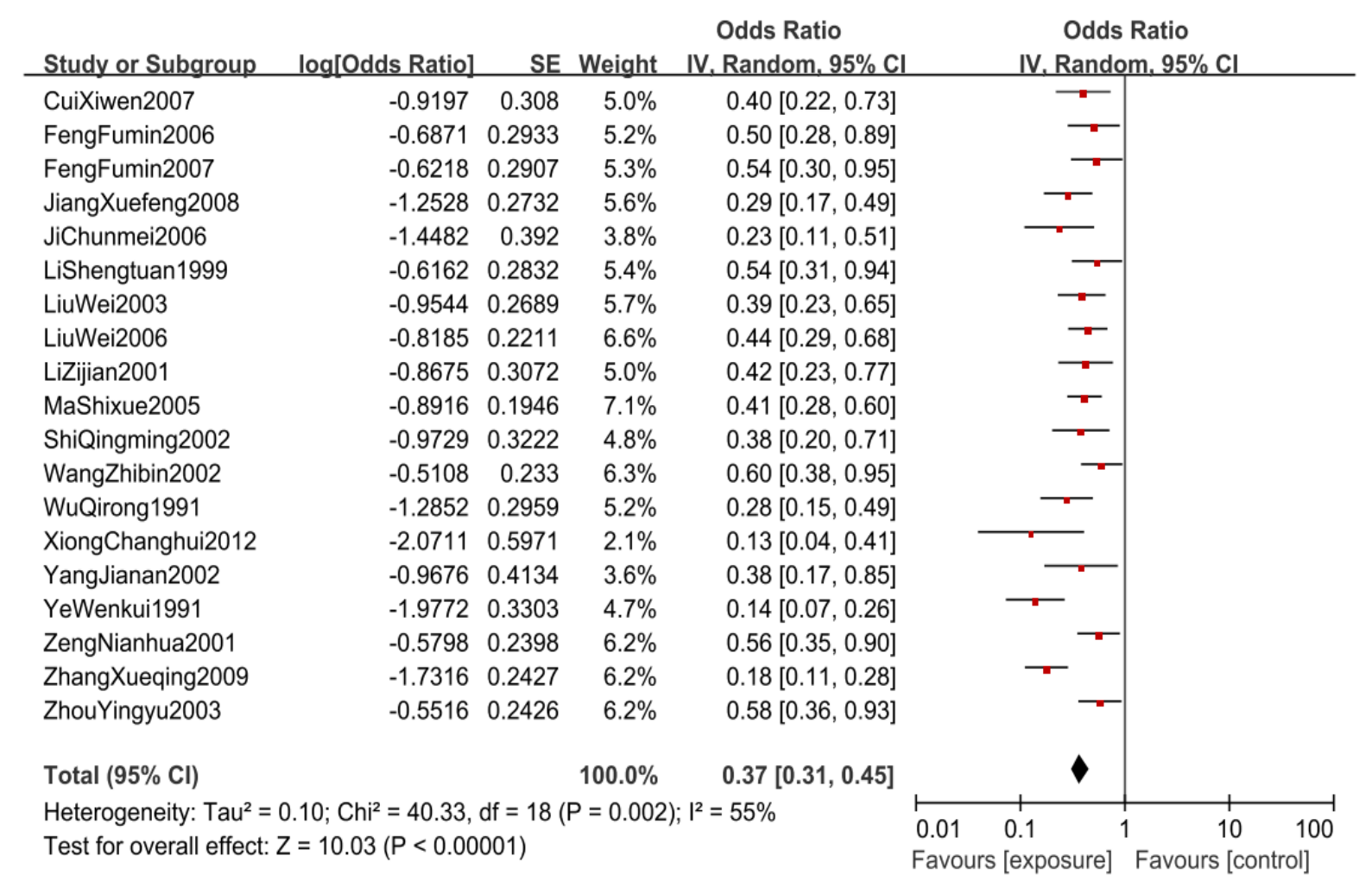

Fig. (6). The pooled estimate of BCG's protection effect in case-control study. 


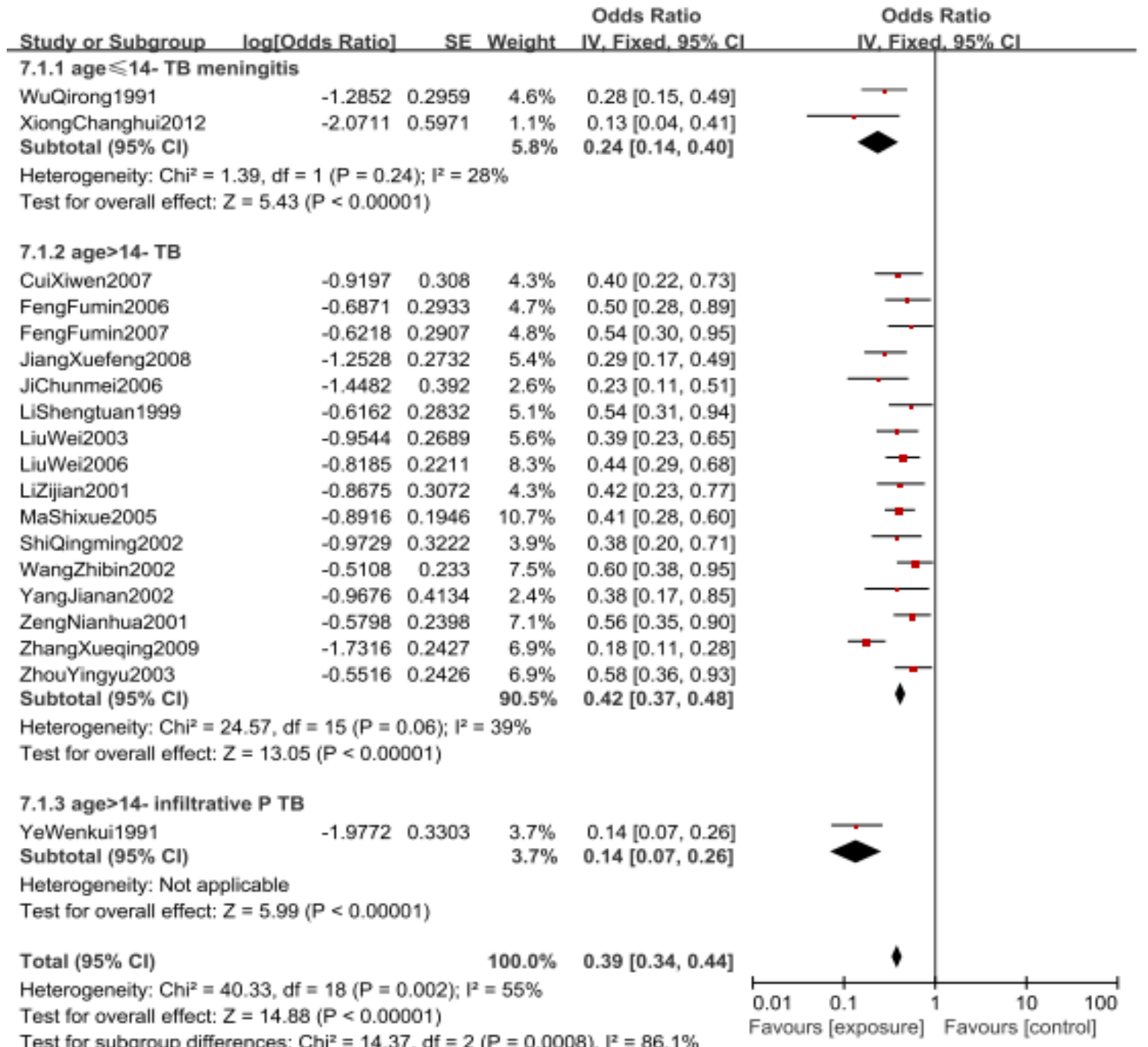

Fig. (7). The pooled estimate of BCG's protection effect in case-control study in group.

of time as year 1990 for subgroup analysis, for the following reasons: Firstly, the change of BCG vaccination procedures: skin scratch method accounted for $20 \%$ and intradermal injections accounted for $80 \%$ in China in 1980s, and the latter had been fully adopted in 1990's [33]. The latter had a twice higher 16-week serum conversion rate than the former based on a survey of BCG vaccination procedure in China in the 1980's [34]. Secondly, The change of population coverage: sample survey of immunization coverage plan in China in 1983 to 1988 showed that: BCG vaccination rate for $12-24$ month old children were $33.9 \%, 50.4 \%, 78.8 \%$, $70 \%, 85.3 \%, 98.4 \%$ respectively, change of vaccination rate among population may affect immunity effects [35].

\section{CONCLUSION}

The available evidence shows positive and definite effect of BCG in preventing TB among Chinese people, while, it should be supported by more studies to avoid publication bias risk. High quality studies are encouraged worldwide to inform immunological agents development and use to cope with TB epidemiology.

\section{CONFLICT OF INTEREST}

This study is funded by the National Natural Science Foundation of China (81102206).

\section{ACKNOWLEDGEMENTS}

We'd like to thank M.S. Xiu Mao and Prof. Youping Li for their prior work contributing to our research background.

\section{REFERENCES}

[1] World Health Organization. Global Tuberculosis Report 2013 http://apps.who.int/iris/bitstream/10665/91355/1/9789241564656_e ng.pdf?ua =1 (Accessed June 5, 2014)

[2] Abubakar, I.; Pimpin, L.; Ariti, C.; Beynon, R.; Mangtani, P.; Sterne, J.; Fine, P. E.; Smith, P. G.; Lipman, M.; Elliman, D.; Watson, J. M.; Drumright, L. N.; Whiting, P. F.; Vynnycky, E.; Rodrigues, L. C. Systematic review and meta-analysis of the current evidence on the duration of protection by bacillus CalmetteGuérin vaccination against tuberculosis. Health. Technol. Assess. 2013, 17 (37), 1-372.

[3] Wells, GA.; Shea, B.; O'Connell, D.; Peterson, J.; Welch, V.; Losos, M.; Tugwell, P. The Newcastle-Ottawa Scale (NOS) for assessing the quality of nonrandomised studies in meta-analyses 
http://www.ohri.ca/programs/clinical_epidemiology/oxford.asp (Accessed June 1, 2014).

[4] Zeng, X. T.; Liu, H.; Chen, X.; Leng,W. D. Meta-analysis of series four: Quality assessment tools for observational study. Chin. J. Evid-Based Cardiovasc. Med. 2012, 4 (4), 297-299.

[5] Guo, C.Z. Effect evolution for BCG vaccine preventing children tuberculosis meningitis. J. Chin. Anti-tuberc. Assess. 1990, 12 (3), 106.

[6] Guo, J.W.; Wu, J.X.; Wang, Y. A controlled study on the effect of bcg on new university entrants. Health Med. Res. Prac., 2006, 3 (2), 7-11.

[7] Hou, D.Q.; Zhou, Y.M. Preventive effect evaluation of BCG against tuberculosis of children. Chin. Med. Fact. Min. 2001, 14 (3), 254-255.

[8] Huang, L.Z.; Chen, S.F. Effects of BCG vaccine preventing children tuberculosis meningitis. J. Chin. Anti-tuberc. Assess. 1988, 10 (3), 127-128

[9] Li, Z.G.; Wu, X.X.; Kang, C.; Wang, J.M. Effect research of BCG vaccination preventing tuberculosis of new students. $J$. Zhangjiakou. Med. Coll. 1998, 15 (3), 21.

[10] Wu, X.R.; Xu, B.P.; Jiao, A.X.; Hu, Y.H.; Yin Q.Q.; Liu, F.; Shen, D.; Feng, W. X.; Jiao, W.W.; Shen, AD. The clinical epidemiological characteristics of pediatric tuberculosis in Beijing Children's Hospital from 2002 to 2010. Chin. J. Evid-Based. Pediatr. 2012, 7(1), 19-24.

[11] Cui, X.W.; Hong, Z.Q.; Shen, Y.P. Case control study on the environmental risk factors for pulmonary tuberculosis of KunShan City. J. Chin. Anti-tuberc. Assess. 2007, 29 (6), 556-558.

[12] Feng, F.M.; Guo, M.; Liu, Q.; Wang, D.; Gao, B.X.; Sun, Y.H.; An, Y. C.; Ji, C. M. Study on mannose-binding protein gene polymorphisms and susceptibility to pulmonary tuberculosis. Zhonghua Liu Xing Bing Xua zazhi 2006, 27 (12), 1082-1085.

[13] Feng, F.M.; Wang, D.; Guo, M.; Liu, Q.; Gao, B.X.; An, Y.C.; Ji, C.M.; Sun, Y.H. A case control study on mannose-binding protein genetic polymorphism and susceptibility to pulmonary tuberculosis. Mod. Prev. Med. 2007, 34(3), 438-440.

[14] Jiang, X.F.; Liu, F.; Gao, Y.J.; Zhang, S.Y.; Li, Y.; Guo, Z.Q.; Chen, C.; Ma, F.; Pei, X. Y. A case-control study on risk factors tuberculosis in Yinchuan city. Chin. J. Prevent. Med. 2008, 42 (2), 90-92.

[15] Ji, C.M.; An, Y.C.; Li, J.; Wang, Y.H. Association of D543N and 3/UTR polymorphism of natural-resistance-associated macrophage protein 1 gene with susceptibility to adult pulmonary tuberculosis in the Hans of North China. Chin. J. Clin. Rehab. 2006, 10 (24), 10-13.

[16] Li, S.T.; Zhang, X.T.; Han, G.H.; Cao, W.C.; Fan, G.Y.; Liu, Y.D. Case control study on the risk factors for pulmonary tuberculosis in servicemen of China. Chin. J. Epid. 1999, 20 (4), 208-211.

[17] Liu, W.; Zhang, C.Y.; Tian, L.; Li, C.Z.; Wu, X.M.; Zhao, Q.M.; Zhang, P.H.; Yang, S.M.; Yang, H.; Cao, W.C. A case-control study on VDR and NRAMP1 gene polymorphisms with susceptibility to pulmonary tuberculosis in Chinese Han population. Bull. Acad. Military (Med. Sci.), 2003, 27(6), 409412,451 .

[18] Liu, W.; Zhang, F.; Zhao, Q.M.; Wu, X.M.; Zhang, C.Y.; Tian, L.; Li, C.Z.; Zhang, P.H.; Yang, H.; Cao, W.C. Case control study on the risk factors for pulmonary tuberculosis in servicemen of China. China. Trop. Med. 2006, 6(4), 569-571.
[19] Li, Z.J.; Liu, Y.D.; Jin, X.H.; Cheng, X.H; Yan, A.H. A casecontrol study for pulmonary tuberculosis in the servicemen of Jinan Command. J. Chin. Anti-tuberc. Assess. 2001, 23(3), 161-163.

[20] Ma, S.X.; Huang, X.Q. Case-control study on risk factors of pulmonary tuberculosis in crowd of rural community in tengzhou. Literat. Info. Prevent. 2005, 11(5), 516-517.

[21] Shi, Q.M.; Ni, J.F.; Tao, F.B. A case-control study on tuberculosis in college students. Chin. J. Dis. Cont. Prevent. 2002, 6(4), 306309.

[22] Wang, Z.B.; Zeng, N.H.; Li, X.G.; Zhu, S.J.; Mao, C.G.; Dang, R. Study on risk factors of pulmonary tuberculosis in southern army of China. China Pub. Health. 2002, 18(1), 85-86.

[23] Wu, Q.R.; Liu, H.Y.; Zhao, X.M.; Zhao, Y.Z.; Li, F.L.; Mu, H.L.; Huang, J.W.; Fan, C.H.; Shen, J.; Xiang, J.W.; Guan, S.X.; Wang, D,M.; Wang, C.F.; Zhu, N.; Wang, G.X. Research between BCG vaccination and the onset of tuberculosis meningitis of children in LiaoNing province. Chin. J. Tuberc. Respir. Dis. 1991, 14(3), 173175.

[24] Xiong, C.H.; Wang, H.Q.; Liang, X.F.; Liao, Z.; Chen, H.Y.; Deng, A.H.; Fu, J.; Zhao, P.P.; Wen, H.R.; Zhou, Y.S. Effect of BCG on prevention of tubercular meningitis in children: a case-control study. Matern. Child Healthc. China, 2012, 21, 3266-3269.

[25] Yang, J.A.; Kan, X.H. Epidemiological study of factors affecting the incidence of TB. Anhui. Med. J. 2002, 23(4), 53-54.

[26] Ye, W.K.; Hao, Y.; Zhang, S. Research of BCG vaccine prevention for infiltrating tuberculosis in young people. Chin. J. Tuberc. Respir. Dis, 1991, 14(5), 295-297.

[27] Zeng, N.H.; Wang, Z.B.; Li, X.G.; Zhao, S.J.; Mao, C.G.; Dang, R. Case control study on the risk factors for pulmonary tuberculosis in servicemen of South China. J. Prevent. Med. Chin. People's. Liberation Army, 2001, 19(3), 178-181.

[28] Zhang, X.Q.; Wang, G.M.; Yu, H.; Zhuang, B. A case-control study on health related behavior and pulmonary tuberculosis. China Trop. Med. 2009, 9(3), 448-486.

[29] Zhou, Y.Y.; Xu, J.; Li, X.M.; Tang, Z.G.; Li, X.P. A Case-control Study on Risk Factors of pulmonary tuberculosis in the enterprises in Changde District. J. Environ. Occup. Med. 2003, 20(4), 294-296.

[30] Balshem H.; Helfand M.; Schünemann H.J.; Oxman A.D.; Kunz R.; Brozek J.; Vist G.E.; Falck-Ytter Y.; Meerpohl J.; Norris S. Guyatt G.H. GRADE guidelines: 3. Rating the quality of evidence. J. Clin. Epidemiol., 2011, 64(4), 401-406.

[31] Guyatt G.H.; Oxman A.D.; Sultan S.; Glasziou P.; Akl E.A.; Alonso-Coello P.; Atkins D.; Kunz R.; Brozek J.; Montori V.; Jaeschke R.; Rind D.; Dahm P.; Meerpohl J.; Vist G.; Berliner E.; Norris S.; Falck-Ytter Y.; Murad M.H.; Schünemann H.J.; GRADE Working Group. GRADE guidelines: 9. Rating up the quality of evidence. J. Clin. Epidemiol., 2011, 64(12), 1311-1316.

[32] Guyatt G.H.; Oxman A.D.; Kunz R.; Woodcock J.; Brozek J.; Helfand M.; Alonso-Coello P.; Glasziou P.; Jaeschke R.; Akl EA.; Norris S.; Vist G.; Dahm P.; Shukla V.K.; Higgins J.; Falck-Ytter Y.; Schünemann H.J.; GRADE Working Group. GRADE guidelines: 7. Rating the quality of evidence-inconsistency. $J$. Clin. Epidemiol., 2011, 64(12), 1294-1302.

[33] Song, W.H. Present situation of BCG vaccination in China. Chin. J. Vac. Immuniz. 1997, 3(3), 133-137.

[34] Yang A.G. Effect observation on skin scratch and intradermal injection method of BCG vaccination. Anhui. Med. J. 1985, 1, 42.

[35] Song,W.H. Overview of BCG vaccination in China in the last forty years. Tuberc. Thorac. Tumor., 1991, 1, 21-26. 